\title{
Clinical Evaluation of Perspiration Reducing Effects of a Kampo Formula, Shigyaku-san, on Palmoplantar Hidrosis
}

\section{Fumino Ninomiya}

Aoki Clinic 4-17, Chuocho, Atami, Shizuoka, 4130015, Japan

\begin{abstract}
Palmoplantar hidrosis is common in patients who are susceptible to strains on the autonomic nervous system, and stress and mental strain have been proven to produce sweating in this population. Shigyaku-san (Sini san, TJ-35: Tsumura \& Co.) is effective for relieving stagnation of 'liver Qi and vital energy' in traditional Chinese medicine theory; this brings about improvement of palmoplantar hidrosis. The effect of Shigyaku-san on 40 patients was evaluated based on changes in palmoplantar sweat volume and skin temperature before and after stress loading. We also measured changes in the palmoplantar sweat volume and skin temperature due to stress load in 35 healthy controls who did not receive Shigyaku-san. Before treatment, the pre-stress sweat volume in patients was larger than that in healthy controls, however, after Shigyaku-san treatment, their pre-stress sweat volume decreased. With stress, the sweat volume increased in both patients and controls, but the net increase in the patients was larger than that in healthy controls. After Shigyaku-san treatment, the net increase of sweat volume due to stress was smaller than that of pretreatment, however, it did not show a significant difference with that of healthy controls. The palmoplantar skin temperature of the patients before treatment was lower than that of healthy controls. Palmoplantar skin temperature rose with stress loading in healthy controls, but decreased in pretreatment patients. Shigyaku-san treatment reduced the palmoplantar perspiration in palmoplantar hidrosis patients at rest and under stress. Furthermore, it also improved other serious complications, especially coldness of the extremities.
\end{abstract}

Keywords: Kampo-palmoplantar hyperhidrosis-Shigyaku-san (sini san)

\section{Introduction}

Palmoplantar hidrosis is common in patients who are susceptible to strain on the autonomic nervous system, and stress and mental strain have been proven to produce sweating in this population. It is known that physiological sweating due to exercise is mediated by stimulation of the sudorific center in the hypothalamus, while sweating due to stress is mediated by stimulation of the sudorific center in the frontal area, which causes an

For reprints and all Correspondence: Fumino Ninomiya, Tel: +81-55781-7285; Fax: +81-557-81-1655; E-mail: hijikata@hen.zaq.ne.jp increase in autonomic nerve strain that leads to palmoplantar sweating $(1,2)$.

Patients with palmoplantar hidrosis often present with lower body coldness, purulent blisters, erythema, facial flushing, atopic dermatitis, constipation and menstrual disorders.

In the present study, I evaluated the effects of Shigyaku-san (Sini san, TJ-35: Tsumura \& Co., Tokyo, Japan) (3) on sweat volume and skin temperature in patients with palmoplantar hidrosis with such troublesome complications. Shigyaku-san seems to be effective for relieving stagnation of liver Qi and vital energy in traditional Chinese medicine (TCM) theory, leading to an improvement in palmoplantar hidrosis and its accompanying symptoms. 


\section{Subjects and Methods}

\section{Preparation of Herbs}

Shigyaku-san (TJ-35) is composed of $5 \mathrm{~g}$ (dry weight/day) Saiko (chai hu, Bupleuri Radix), $4 \mathrm{~g}$ Shakuyaku (shao yao, Paeoniae Radix), $2 \mathrm{~g}$ Kijitsu (zhi shi, Aurantii Fructus Immaturus) and $1.5 \mathrm{~g}$ Kanzo (gan cao, Glycyrrhizae Radix). All herb mixtures were extracted with boiling water and spray-dried to generate granules by adding dextrose.

\section{Treatment}

At the Aoki Clinic, patients with palmoplantar hidrosis complicated with lower body coldness, purulent blisters, erythema, facial flushing, atopic dermatitis, constipation or menstrual disorders were informed of the study protocol and 40 patients (13 male, 27 female: $34 \pm 19$ years old) agreed to participate. TJ-35 was administered to the patients either as a first treatment, or was added to other Kampo medicines after patients showed a poor response to various other Kampo medicines (Tsumura \& Co.). The palmoplantar sweat volume and skin temperature of all patients were measured before the administration of TJ-35. The efficacy of the treatment was evaluated at 2,4 and 8 weeks after starting the administration of TJ-35 by measuring the sweat volume and skin temperature.

\section{Sweat Volumes}

Sweat Volume and skin temperature were measured under both pre- and post- stress conditions. The mental stress test consisted of counting backwards from 100 by $7 \mathrm{~s}$. Sweat volume was measured using a moisture sensor for the skin (MY-707S: Sato Shouji Inc., Japan) (4-6) which expresses the moisture or sweat volume on the skin

Table 1. Perspiration change by Shigyaku-san treatment

\begin{tabular}{|c|c|c|c|c|}
\hline & \multicolumn{2}{|c|}{ Shigyaku-san (-) } & \multicolumn{2}{|c|}{ Shigyaku-san (+) } \\
\hline & tress & Post-stress & re-stress & Post-stress \\
\hline \multicolumn{5}{|l|}{ Patients) } \\
\hline alm & $42.3 \pm 7.5^{\mathrm{tat}}$ & $46.7 \pm 7.3^{\dagger+\dagger, \text { 小t }}$ & $36.6 \pm 6.1^{\dagger+\dagger,+1 t}$ & $40.2 \pm 6.9^{\S \S}$ \\
\hline lantaris & $41.7 \pm 7.4 \mathrm{ttt}$ & $45.7 \pm 7.8^{\dagger, \text { tat }}$ & $37.2 \pm 6.0^{\dagger \dagger \dagger,+1+t}$ & $39.6 \pm 4.0^{\S}$ \\
\hline \multicolumn{5}{|c|}{ (Healthy controls) } \\
\hline alm & $32.7 \pm 2.3$ & $34.6 \pm 3.2^{*}$ & & \\
\hline lantaris & $31.9 \pm 3.2$ & $33.3 \pm 3.9^{* *}$ & & \\
\hline \multicolumn{5}{|c|}{ 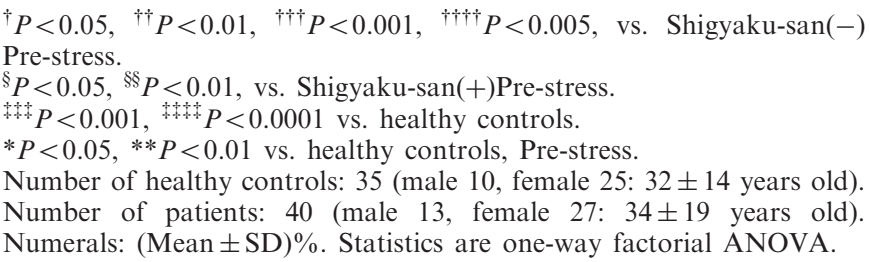 } \\
\hline
\end{tabular}

surface as a percentage against a cube taking the epidermis as $100 \%$. Skin temperature was measured with a thermometer (IR-TE: Waterproof Handy Infrared Thermometer, Chino Co., Japan).

Statistical Analysis was performed by analysis of variance (one-way factorial ANOVA).

\section{Results}

Forty patients (13 male, 27 female: $34 \pm 19$ years old) who were diagnosed as having palmoplantar hidrosis and complicated with lower body coldness, purulent blisters, erythema, facial flushing, atopic dermatitis, constipation or menstrual disorders were administered Shigyaku-san. The troublesome complications were satisfactorily resolved within 2-8 weeks. The sweat volume and skin temperature changed gradually in 8 weeks and data at 8 weeks are used for the following analysis.

\section{Perspiration}

The sweat volume of patients before treatment and at rest was significantly larger than that of healthy controls $(P<0.0001)$. After Shigyaku-san treatment, however, the patients' sweat volume at rest decreased significantly compared with pretreatment levels $(P<0.001)$, but remained significantly larger than that of healthy controls $(P<0.001)$ (Table 1).

Under stress conditions, sweat volume increased significantly even in healthy controls $(P<0.05)$, but the net increase of sweat volume in the patients was larger than that in healthy controls $(P<0.01)$. After Shigyakusan treatment, the net increase in sweat volume under stress conditions was significantly smaller than during the pretreatment period $(P<0.05)$, and the net increase did not show significant difference compared with that of healthy controls; these tendencies were observed on both palms and plantars.

Table 2. Skin temperature change by Shigyaku-san treatment

\begin{tabular}{lcclll}
\hline & \multicolumn{2}{c}{ Shigyaku-san $(-)$} & & \multicolumn{2}{c}{ Shigyaku-san $(+)$} \\
\cline { 2 - 3 } & Pre-stress & Post-stress & & Pre-stress & Post-stress \\
\hline Patients) & & & & \\
Palm & $32.8 \pm 2.4^{*}$ & $31.2 \pm 2.6^{\dagger,}$ & & $31.9 \pm 2.0^{\dagger}$ & $31.6 \pm 2.3$ \\
Plantaris & $26.0 \pm 3.4^{*}$ & $25.9 \pm 3.6^{* *}$ & & $25.9 \pm 3.6$ & $26.8 \pm 3.5$ \\
(Healthy controls) & & & & \\
Palm & $33.2 \pm 3.8$ & $36.0 \pm 5.1^{*}$ & & \\
Plantaris & $30.0 \pm 3.6$ & $32.6 \pm 3.4^{* *}$ & & \\
\hline
\end{tabular}

${ }^{\dagger} P<0.05$ vs. Shigyaku san (-) Pre-stress.

柿 $P<0.01,+\$ P<0.001$ vs. healthy controls.

$* P<0.05, * * P<0.01$ vs. healthy controls, Pre-stress.

Number of healthy controls: 35 (male 10, female 25: $32 \pm 14$ years old). Number of patients: 40 (male 13, female 27: $34 \pm 19$ years old). Numerals: (Mean $\pm \mathrm{SD})^{\circ} \mathrm{C}$. Statistics are one-way factorial ANOVA. 


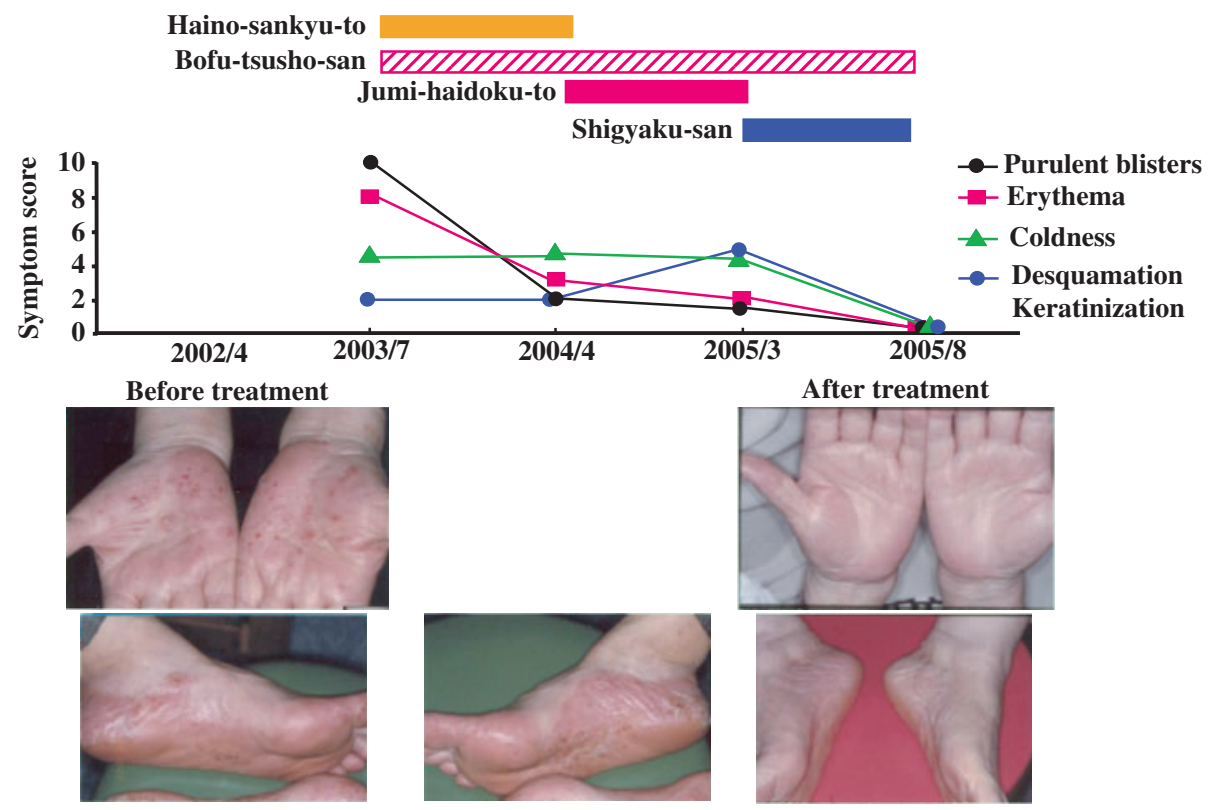

Figure 1. A 57-year-old Japanese female.

\section{Skin Temperature}

Skin temperature, especially that on patients' plantars, did not show as notable changes as perspiration with Shigyaku-san treatment (Table 2).

The skin temperature of patients before treatment was significantly lower than that of healthy controls on both palms $(P<0.01)$ and plantars $(P<0.001)$. In healthy control subjects under stress, the skin temperature rose and showed a significant difference both on palms $(P<0.05)$ and on plantars $(P<0.01)$. In contrast, in patients before treatment, it decreased significantly with stress on the palms $(P<0.05)$. After Shigyaku-san treatment, the skin temperature of the palms decreased with stress (not significant).

\section{Case Reports}

I present here the clinical courses of two patients with palmoplantar hidrosis and complications. The diagnosis of palmoplantar hidrosis was delayed because they were severely complicated with lower body coldness, purulent blisters, erythema, facial flushing and other symptoms. Both of them were diagnosed as having stagnation of liver Qi by TCM theory.

\section{Case 1: A 57-year-old Japanese female (Fig. 1)}

This patient had been suffering from multiple symptoms including purulent blisters and erythema after undergoing menopause 1 year earlier. At her first visit, she complained of lower back pain and arthralgia and also showed constipation and mild hyperlipidemia. In addition, she complained of fullness, tenderness and discomfort of the hypochondrium upon palpation. She also noted coldness of the extremities. Her symptoms became worse under stress. During Kampo treatment, she described intensity of four symptoms; purulent blisters, erythema, coldness and skin lesions (desquamation and keratinization), between 0 (no symptom) and 10 (severest possible).

The patient was treated with Haino-sankyu-to (pai nong san ji tang, TJ-122) [4 g (dry weight/day) Platycodi Radix, $3 \mathrm{~g}$ Paeoniae Radix, $3 \mathrm{~g}$ Glycyrrhizae Radix, $3 \mathrm{~g}$ Zizyphi Fructus, $3 \mathrm{~g}$ Aurantii Fructus Immaturus, $1 \mathrm{~g}$ Zingiberis Rhizoma] (7) for her blisters, and with Bofu-tsusho-san (fang feng tong sheng san, TJ-62) [2 g(dry weight/day) Scutellariae Radix, 2 g Glycyrrhizae Radix, $2 \mathrm{~g}$ Platycodi Radix, $2 \mathrm{~g}$ Gypsum Fibrosum, $2 \mathrm{~g}$ Atractylodis Rhizoma, $1.5 \mathrm{~g}$ Rhei Rhizoma, $1.2 \mathrm{~g}$ Schizonepetae Spica, $1.2 \mathrm{~g}$ Gardeniae Fructus, $1.2 \mathrm{~g}$ Paeoniae Radix, 1.2 g Cnidii Rhizoma, 1.2 g Angelicae Radix, $1.2 \mathrm{~g}$ Menthae Herba, $1.2 \mathrm{~g}$ Saposhnikoviae Radix, $1.2 \mathrm{~g}$ Ephedrae Herba, 1.2 g Forsythiae Fructus, $0.3 \mathrm{~g}$ Zingiberis Rhizoma, $3 \mathrm{~g}$ Talcum Crystallinum, $0.7 \mathrm{~g}$ Natrii Sulfus] (8) for her constipation and hyperlipidemia, resulting in marked improvement of the blisters, erythema and constipation. TJ-62 had been continued as constipation recurred every time she tried to stop it. However, the poor blood circulation in the legs did not improve.

The patient's treatment was then changed to Jumihaidoku-to (shi wei bai du tang, TJ-6) [3 g (dry weight/ day) Platycodi Radix, $3 \mathrm{~g}$ Bupleuri Radix, $3 \mathrm{~g}$ Cnidii Rhizoma, $3 \mathrm{~g}$ Poria, $1.5 \mathrm{~g}$ Saposhnikoviae Radix, $1 \mathrm{~g}$ Glycyrrhizae Radix, $1 \mathrm{~g}$ Schizonepetae Spica, $1 \mathrm{~g}$ Zingiberis Rhizoma, $3 \mathrm{~g}$ Quercus Cortex, $1.5 \mathrm{~g}$ Araliae Cordatae Rhizoma] (9) instead of TJ-122, which produced a slight improvement in the blisters and erythema, 


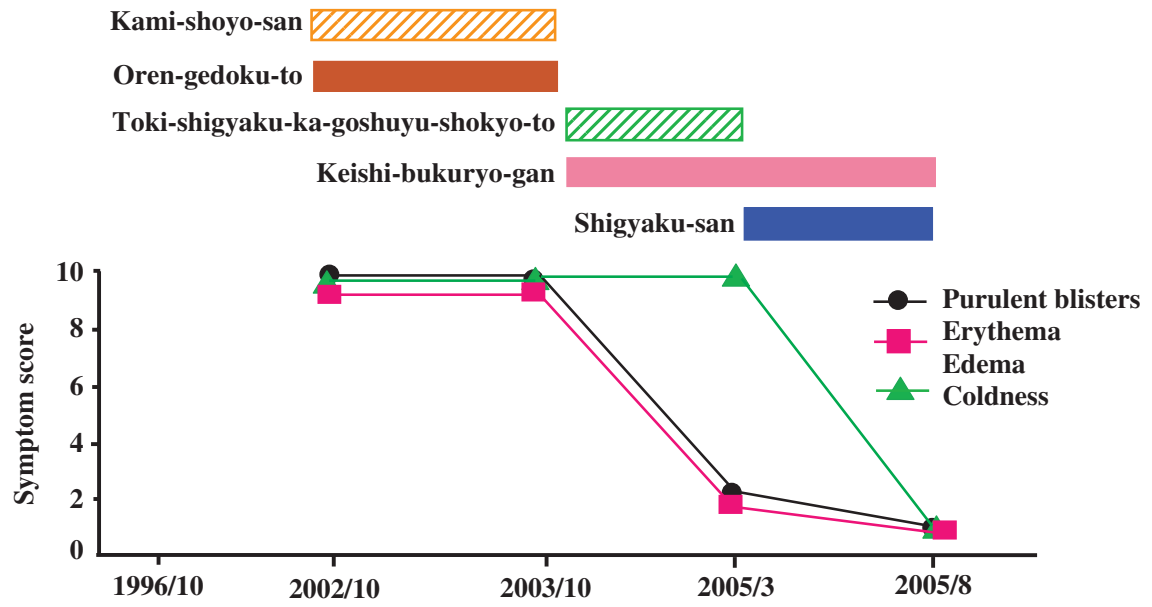

Figure 2. A 67-year-old Japanese female.

but the sweating and coldness of the extremities still persisted. Number of symptoms being disappeared, palmoplantar hidrosis was finally diagnosed and TJ-35 was added to her regimen in place of TJ-6. Before starting TJ-35, pre-stress sweat volume of her palms was $40.0 \%$ and plantars $39.7 \%$, and that of post-stress state, $47.7 \%$ and $46.7 \%$. Pre-stress skin temperature of her palms and plantars was $31.5^{\circ} \mathrm{C}$ and $25.0^{\circ} \mathrm{C}$, and that of post-stress state, $31.0^{\circ} \mathrm{C}$ and $24.5^{\circ} \mathrm{C}$. In 4 weeks of TJ-35 treatment, pre-stress sweat volume of her palms was $35.2 \%$ and plantars $38.3 \%$, and that of post-stress state, $39.5 \%$ and $40.5 \%$. Pre-stress skin temperature of her palms and plantars was $31.0^{\circ} \mathrm{C}$ and $27.0^{\circ} \mathrm{C}$, and that of post-stress state, $31.0^{\circ} \mathrm{C}$ and $26.5^{\circ} \mathrm{C}$. In 8 weeks of treatment, pre-stress sweat volume of her palms was $34.1 \%$ and plantars $37.5 \%$, and that of post-stress state, $36.6 \%$ and $39.0 \%$. Pre-stress skin temperature of her palms and plantars was $33.0^{\circ} \mathrm{C}$ and $28.5^{\circ} \mathrm{C}$, and that of post-stress state, $33.0^{\circ} \mathrm{C}$ and $28.5^{\circ} \mathrm{C}$. Her hyperhidrosis and coldness of the extremities resolved.

\section{Case 2: A 67-year-old Japanese female (Fig. 2)}

This patient first visited our clinic on October 16th, 2002 with a 10-year history of multiple symptoms with purulent blisters, facial erythema and flushing. She complained of discomfort in going outside due to severe coldness of the extremities and difficulties with defecation due to hemorrhoids. During Kampo treatment, she described intensity of three symptoms; purulent blisters, skin lesion (erythema and edema) and coldness between 0 (no symptom) and 10 (severest possible). As shown in Fig. 2, Kami-shoyo-san (jia wei xiao yao san, TJ-24) [3 g (dry weight/day) Bupleuri Radix, $3 \mathrm{~g}$ Paeoniae Radix, $3 \mathrm{~g}$ Atractylodis Lanceae Rhizoma, $3 \mathrm{~g}$ Angelicae Radix, $3 \mathrm{~g}$ Poria, $2 \mathrm{~g}$ Gardeniae Fructus, $2 \mathrm{~g}$ Moutan Radix, 1.5 g Glycyrrhizae Radix, $1 \mathrm{~g}$ Zingiberis Rhizoma, $1 \mathrm{~g}$ Menthae Herba] (10) and Oren-gedoku-to (huang lian jie du tang, TJ-15) [3g (dry weight/day) Scutellariae Radix, $2 \mathrm{~g}$ Coptidis Rhizoma, $2 \mathrm{~g}$ Gardeniae Fructus, $1.5 \mathrm{~g}$ Phellodendri Cortex] (11) were administered, but no response was acheived. She was then treated with Toki-shigyaku-ka-goshuyu-shokyo-to (dang gui si ni jia wu zhu yu sheng jiang tang, TJ-38) [5 g (dry weight/ day) Zizyphi Fructus, $3 \mathrm{~g}$ Cinnamomi Cortex, $3 \mathrm{~g}$ Paeoniae Radix, $3 \mathrm{~g}$ Angelicae Radix, $3 \mathrm{~g}$ Akebiae Caulis, 2 g Glycyrrhizae Radix, $2 \mathrm{~g}$ Evodiae Fructus, $2 \mathrm{~g}$ Asiasari Radix, $1 \mathrm{~g}$ Zingiberis Rhizoma] (12) for her cold limbs together with Keishi-bukuryo-gan (gui zhi fu ling wan, TJ-25) [3 g (dry weight/day) Cinnamomi Cortex, $3 \mathrm{~g}$ Paeoniae Radix, $3 \mathrm{~g}$ Persicae Semen, $3 \mathrm{~g}$ Poria, $3 \mathrm{~g}$ Moutan Radix] (13), which is usually effective for 'upper fire' and lower body coldness. The patient's blisters and erythema resolved, but stopping TJ-25 worsened the skin lesions and TJ-25 was continued. The sweating and coldness of the limbs still persisted, leading to the diagnosis of palmoplantar hidrosis. Finally, TJ-38 was replaced by TJ-35. Before starting TJ-35, pre-stress sweat volume of her palms was $37.6 \%$ and plantars $40.7 \%$, and that of post-stress state, $50.1 \%$ and $43.9 \%$. Pre-stress skin temperature of her palms and plantars was $30.5^{\circ} \mathrm{C}$ and $23.5^{\circ} \mathrm{C}$ and that of post-stress state, $30.0^{\circ} \mathrm{C}$ and $23.0^{\circ} \mathrm{C}$. In 2 weeks of TJ-35 treatment, pre-stress sweat volume of her palms was $34.9 \%$ and plantars $38.6 \%$, and that of post-stress state, $40.3 \%$ and $41.2 \%$. Pre-stress skin temperature of her palms and plantars was $30.0^{\circ} \mathrm{C}$ and $24.5^{\circ} \mathrm{C}$, and that of post-stress state, $30.0^{\circ} \mathrm{C}$ and $24.0^{\circ} \mathrm{C}$. In 4 weeks of treatment, pre-stress sweat volume of her palms was $33.1 \%$ and plantars $37.5 \%$, and that of post-stress state, $34.7 \%$ and $40.2 \%$. Pre-stress skin temperature of her palms and plantars was $30.5^{\circ} \mathrm{C}$ and $26.0^{\circ} \mathrm{C}$, and that of post-stress state, $30.5^{\circ} \mathrm{C}$ and $25.5^{\circ} \mathrm{C}$. TJ-35 treatment brought about the complete resolution of coldness of the extremities, and the patient's palmoplantar hidrosis was almost completely cured. 


\section{Discussion}

Shigyaku-san is a typical formula for constraint and stagnation of liver Qi (3). In TCM, Qi is one of the fundamental substances in the body. Other fundamental substances are 'Blood' and 'Body fluids'. Qi promotes circulation of Blood and Body fluids to support vital activity. The concept of Qi may correlate to autonomic nervous system in Western medicine (14).

Shigyaku-san is used to treat conditions in which liver Qi stagnates around the hypochondrium and upper abdomen, inhibiting the spreading of Yang Qi to the extremities. (Yang Qi is the capacity of the body to generate and maintain warmth and circulation.) Coldness of the extremities in spite of warmth of the body is related to the inability of Yang Qi to move outward due to the stagnation of liver Qi. In other words, stagnation of liver Qi is the major causative factor of coldness of the extremities (15-17).

Nakamura states that Shigyaku-san is prescribed for the aforementioned symptoms or for conditions such as hypochondrial febrile syndrome, fullness, tenderness or discomfort of the hypochondrium due to Qi stagnation, a bitter taste, dry mouth, tension of the shoulder and back muscles, fullness of the upper abdomen, psychotic manifestations, coldness of the limbs, spontaneous palmoplantar sweating, depression, irritability and fatigue (17).

From the viewpoint of TCM, patients prone to palmoplantar sweating due to stress or mental strains are diagnosed as having liver Qi stagnation leading to a transformation into heat syndrome. This heat subsequently ascends, causing such 'upper fire' symptoms as facial erythema and flushing. Fullness, tenderness or discomfort of the hypochondrium area is also commonly observed in these patients due to liver Qi stagnation. When liver Qi stagnates, body Qi does not flow smoothly. Thus, according to TCM theory, it becomes difficult for the heart Yang to descend and for the kidney fluid to ascend, resulting in a state in which the kidneys and heart fail to maintain a mutual balance, followed by the simultaneous existence of 'upper fire' and lower coldness. Indeed, flushing, blisters, atopic dermatitis-like changes of the face, cold limbs, constipation and dysmenorrhea are commonly observed in patients with palmoplantar hidrosis. Many patients with this disease have been found to suffer cold extremities and dysregulation of the autonomic nervous system and to be prone to palmoplantar sweating under stress; these have been confirmed by the present study.

Among the components of Shigyaku-san, Saiko (chai hu, Bupleuri Radix) serves to disperse liver Qi by removing stagnation, Kijitsu (zhi shi, Aurantii Fructus Immaturus), to break up stagnant Qi, Shakuyaku (shao yao, Paeoniae Radix), to tonify liver Yin and Kanzo (gan cao, Glycyrrhizae Radix), to provide harmony of the herbs (18). (Liver Yin stands for Blood and all other fluids in the body which nurture and moisten the organs and tissues.)

The administration of Shigyaku-san brought about excellent improvement by resolving the stagnated liver Qi and thereby achieving a smooth body Qi flow (19). Although warming prescriptions were unable to cure coldness in Case 2 and anti-inflammatory prescriptions for purulent blisters and erythema did not work in Case 1, the administration of Shigyaku-san brought about excellent improvement in the patients' symptoms.

\section{Acknowledgement}

The author would like to thank Yasuyo Hijikata, MD, Ph.D, for her assistance and encouragement.

\section{References}

1. Masumura T, Shinomiya S, Kamachi H, Kobayashi T, Tsuda T. Seishin'bunretsubyo ni okeru Ball Catch ji no hakkan-hanno: kenjosha tono hikaku. Hakkangaku 2002;9:25-8 (Japanese).

2. Shinomiya S. Seishinka ryoiki ni okeru seishinsei-hakkan-gensho no rinsho-oyo. Hakkangaku 1999;6:38-43 (Japanese).

3. Bensky D, Barolet R. Chinese Herbal Medicine Formulas \& Strategies. Seattle: Eastland Press, 1990, 145-6.

4. Kita K. Kyokusho hakkanryo renzokukiroku sochi no rinsho oyo: Jiritsu shinkeishikkan wo chushin to shite. Jiritsu-shinkei 1997;34:304-10 (Japanese).

5. Ohashi T, Uono K. Seishinsei hakkan gensho: Sokuteiho to rinsho oyo. Nagoya: Lifemedicom, 1993 (Japanese).

6. Kita K. Hifu kekkankei jiritsushinkei kinokensa. In: Japan Jiritsushinkei Gakkai (ed). Jiritsushinkei Kinokensa. Tokyo: Bunkodo, 1992, 214-8 (Japanese).

7. Bensky D, Gamble A. Chinese Herbal Medicine MATERIA MEDICA. revised edn. Seattle: Eastland Press, 1992, 196, 331, 323, 322, 234, 36.

8. Bensky D, Barolet R. Chinese Herbal Medicine Formulas \& Strategies. Seattle: Eastland Press, 1990, 58.

9. Bensky D, Gamble A. Chinese Herbal Medicine MATERIA $M E D I C A$. revised edn. Seattle: Eastland Press, 1992, 196, 323, 49, 31, 266, 36, 131, 32, 155.

10. Bensky D, Barolet R. Chinese Herbal Medicine Formulas \& Strategies. Seattle: Eastland Press, 1990, 148.

11. Bensky D, Barolet R. Chinese Herbal Medicine Formulas \& Strategies. Seattle: Eastland Press, 1990, 78.

12. Bensky D, Barolet R. Chinese Herbal Medicine Formulas \& Strategies. Seattle: Eastland Press, 1990, 217.

13. Bensky D, Barolet R. Chinese Herbal Medicine Formulas \& Strategies. Seattle: Eastland Press, 1990, 322.

14. Terasawa K. Evidence-based Reconstruction of Kampo Medicine: Part II-The concept of Sho. Evidbased Complement Altern Med 2004;1:119-123.

15. Kotei Daikei Somon: Chiba: Toyo Gakujutsu Shuppansha 1990, 1: 323; 2: 333 (Japanese).

16. Yamamoto I. Toi zatsuroku, Vol. 2. Tokyo: Ryogen Co, 1981, 181-215 (Japanese).

17. Nakamura K. Dictionary for Japanese and Chinese Herbs (Wakan'yaku Hoi Jiten). Tokyo: Midorishobo, 2004, 303 (Japanese).

18. Itoh Y. Clinical application of Shigyaku-san. Kampo no Rinsho 1988;35:10-19 (Japanese).

19. Kobe Chuigakukenkyukai (ed). Clinical Research of Chinese Traditional Medicine - Prescription. Tokyo: Ishiyaku Shuppan, 1992, 109-110 (Japanese).

Received December 27, 2005; accepted January 16, 2007 


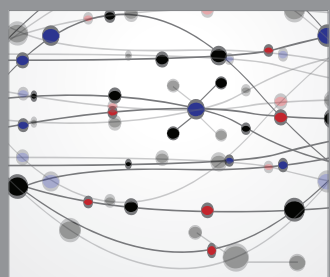

The Scientific World Journal
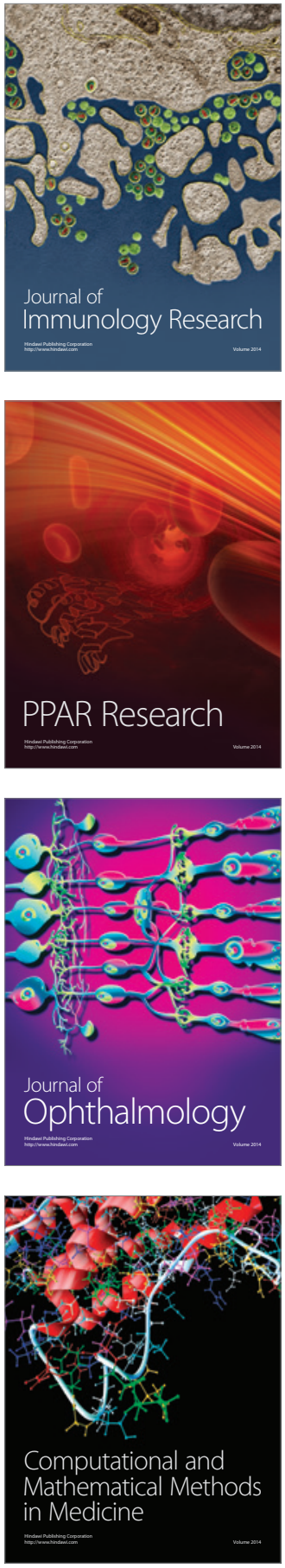

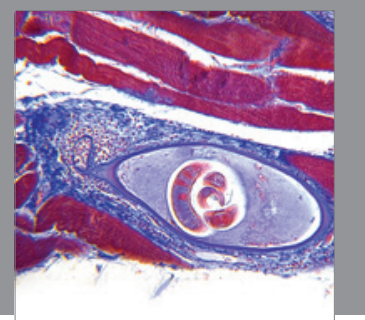

Gastroenterology

Research and Practice
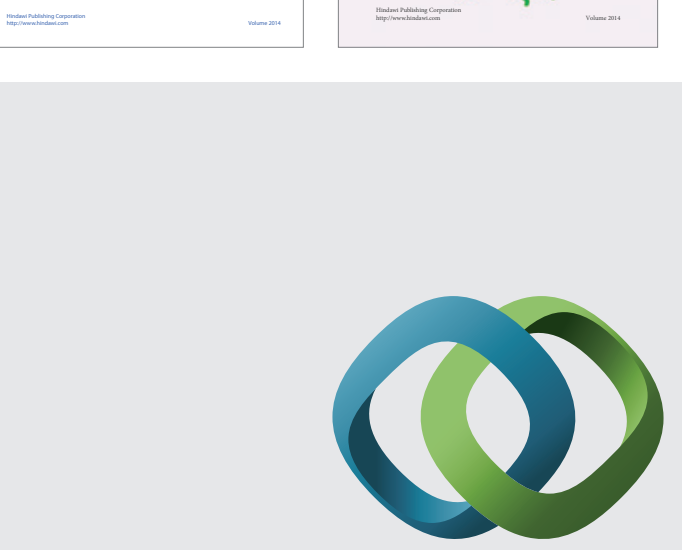

\section{Hindawi}

Submit your manuscripts at

http://www.hindawi.com
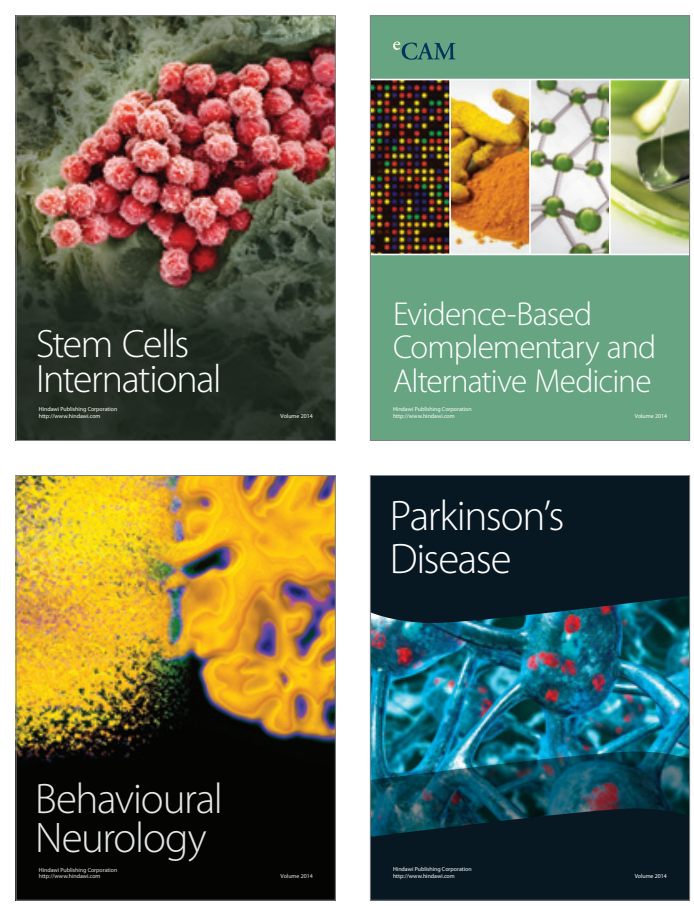

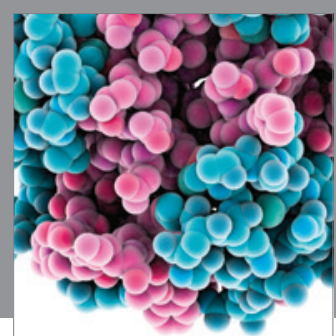

Journal of
Diabetes Research

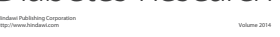

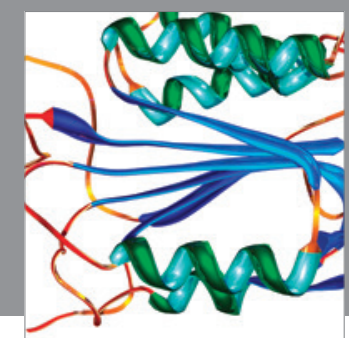

Disease Markers
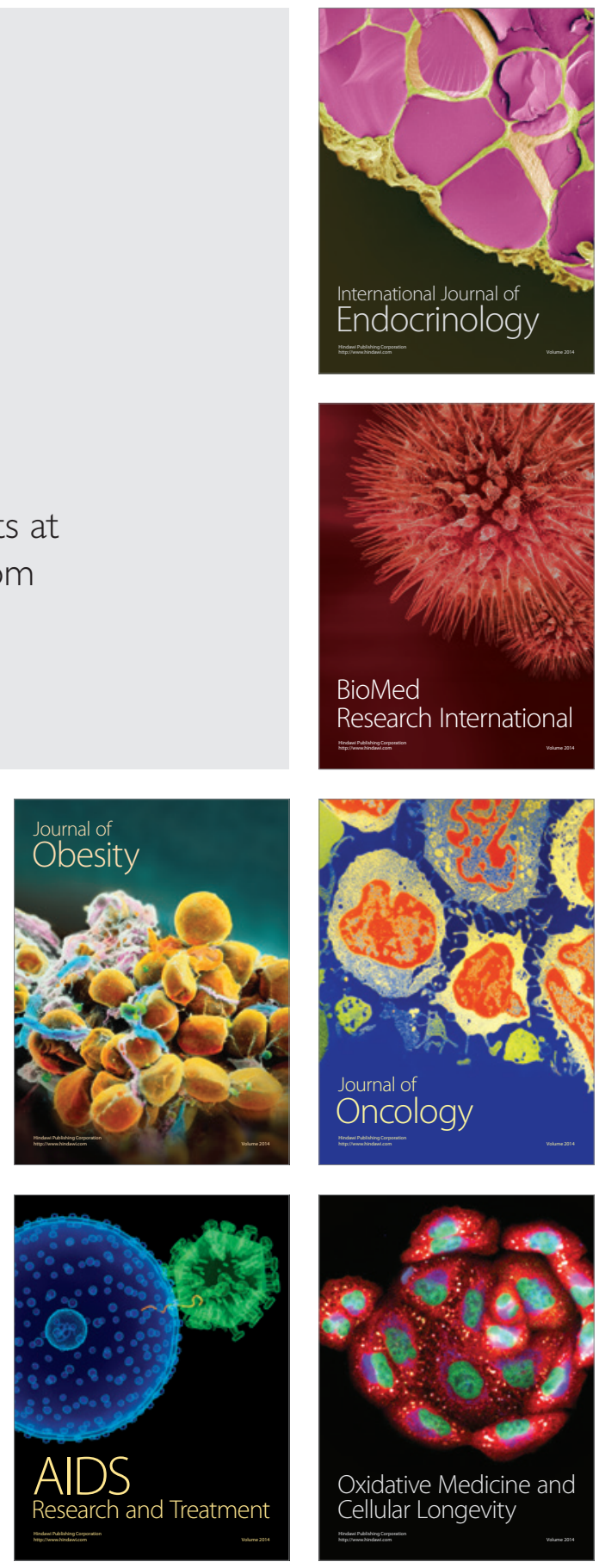